2004-01-01

\title{
Management of marine wildlife disturbance
}

Kelly, C::0000-0002-3809-225X

http://hdl.handle.net/10026.1/4334

10.1016/j.ocecoaman.2004.03.001

Ocean \& Coastal Management

Elsevier BV

All content in PEARL is protected by copyright law. Author manuscripts are made available in accordance with publisher policies. Please cite only the published version using the details provided on the item record or document. In the absence of an open licence (e.g. Creative Commons), permissions for further reuse of content should be sought from the publisher or author. 


\title{
Management of marine wildlife disturbance
}

\author{
C. Kelly ${ }^{\mathrm{a}}$, G.A. Glegg ${ }^{\mathrm{a}, *}$, C.D. Speedie ${ }^{\mathrm{b}}$ \\ ${ }^{a}$ School of Earth, Ocean and Environmental Sciences, University of Plymouth, Drake Circus, \\ Plymouth PL4 8AA, UK \\ ${ }^{\mathrm{b}}$ MER Consultants, Waterside House, Falmouth Road, Penryn TR10 8BE, UK
}

\begin{abstract}
In recent years, concerns have been raised about the health and status of a range of marine species in UK waters, including the bottlenose dolphin (Tursiops truncatus) and basking shark (Cetorhinus maximus). Disturbance and harassment from increasing inshore leisure traffic and a fascinated public have been identified as potential threats to these large marine species. This concern is coupled with a legislative framework that is perceived to be less effective in protecting key species than it could be, and difficult to enforce. This study examined the extent of anthropogenic disturbance to a range of marine wildlife in inshore waters around the South West peninsula and investigated people's knowledge of existing legislation and its perceived suitability. The results revealed a low level of reported incidents and a lack of awareness of marine protection legislation amongst all sectors. Confusion over the reporting process, roles and responsibilities was also identified. This study therefore recommends widespread promotion of the provisions of existing legislation, coupled with a more integrated approach between organisations involved in the management of the marine environment. It also highlights the availability of a range of management options including education and codes of practice.

(C) 2004 Elsevier Ltd. All rights reserved.
\end{abstract}

\section{Introduction}

Marine wildlife, and in particular the 'charismatic megafauna' such as the bottlenose dolphin (Tursiops truncatus) and basking shark (Cetorhinus maximus),

*Corresponding author. Fax: + 44-1752-232406.

E-mail address: gglegg@plymouth.ac.uk (G.A. Glegg). 
have been the subject of increasing public awareness and conservation interest over the past decade [1,2]. This surge in public interest has brought with it a number of positive benefits, including increased levels of protection and reduction of direct threats. However, by stimulating public interest, conservationists may have inadvertently contributed to an increase in the levels of disturbance [1]. This issue is particularly relevant to the South West of England, given its status as one of the most popular holiday destinations in the UK, and the growing demand for marine 'nature watching' and 'ecotourism' experiences [3,4].

This concern is coupled with a legislative structure that is perceived to be less effective than it could be and difficult to enforce [5,6]. Recent changes in statutory legislation, brought about through the Countryside and Rights of Way Act 2000, now afford better protection to specific marine species by making it an offence to cause 'reckless or intentional disturbance'. However, there are still many inherent problems in bringing a successful prosecution to court $[1,6]$. National and regional Biodiversity and Species Action Plans have also called for a better understanding of the threats to species such as the basking shark, amongst others.

This research aims to establish the levels and origins of one of those threats; harassment of marine wildlife, to allow comparisons of a range of conservation measures to be made and to provide an opportunity to evaluate existing legislation and codes of conduct. A number of biological definitions of harassment already exist [7,8] and therefore this work does not provide further definitions but attempts to establish the form, or forms that harassment and disturbance take and investigate any discernible patterns that may emerge in terms of those responsible. To do this it considers the observed frequency and nature of harassment and disturbance and whether current methods for prevention are adequate. Although the separate issue of 'bycatch' from commercial fisheries operations is closely related in terms of species disturbance, it is considered beyond the scope of this research and has therefore not been included.

\subsection{Geographic setting}

The South West peninsula of England is loosely defined as the counties of Devon, Cornwall, Somerset, Dorset and Wiltshire (Fig. 1). The inshore waters of the South West peninsula have few year-round resident cetacean populations. However, there are a number of transient, semi-resident and loosely grouped pods of the bottlenose dolphin (Tursiops truncatus). Occasional visitors include the white beaked dolphin (Lagenorhynchus albirostris), Risso's dolphin (Grampus griseus), harbour porpoise (Phocoena phocoena), killer whale or orca (Orcinus orca) and long finned pilot whale (Globicephala melas) [3]. Other dolphin species and some whales have also been recorded in the Celtic Sea [9].

Basking sharks are also occasionally seen in waters off the South West peninsula during the summer months [10] as are resident grey seals (Halichoerus grypus). In his study of disturbance to grey seals at haul-out sites, Westcott [11], 


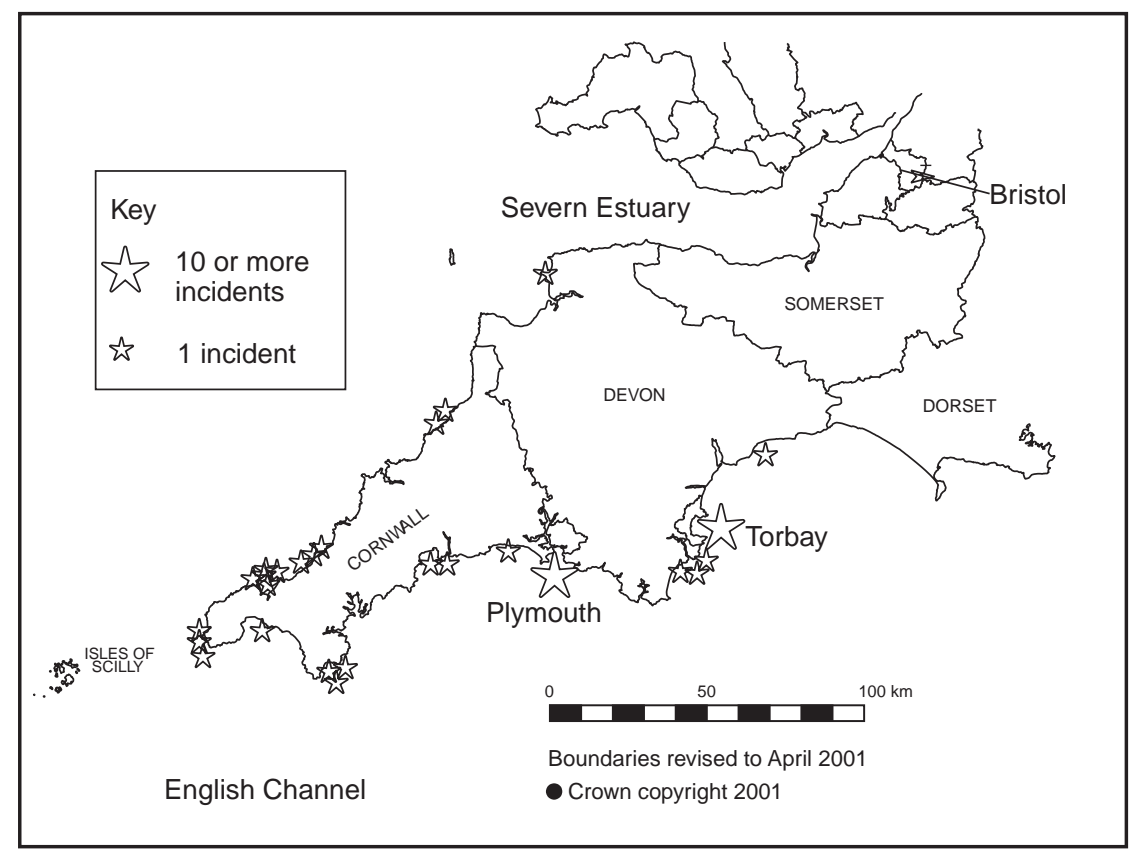

Fig. 1. The study area around the South West peninsula of England showing the location of reported harassment or disturbance incidents. Torbay, the geographic focus of the questionnaire survey, is also shown.

suggests that the population centred on the South West peninsula consists of not more than 500 highly mobile individuals living at the southern edge of their range.

\section{Disturbance issues}

Potential disturbance to, and harassment of, species in the marine environment may take many forms, from accidental driving of an animal from its feeding grounds to 'bycatch' as a result of commercial fisheries (a separate issue, beyond the scope of this research). Definitions of the terms 'harassment' and 'disturbance' are open to interpretation. The Concise Oxford Dictionary defines 'disturbance' as

interruption of tranquillity, agitation; tumult, uproar, outbreak; (Law) molestation, interference with rights or property

and 'harass' as

vex by repeated attacks; trouble, worry [12]. 
Clearly, the two words although similar, may have subtly different meanings in that to 'disturb' may refer to a single event, which may or may not be repeated, whereas the definition of 'harass' is clear in its description of repeated events. The Wildlife and Countryside Act 1981 as amended by the Countryside and Rights of Way Act 2000 uses the word 'disturbance' which could therefore be interpreted as a single or repeated event.

Biological definitions of disturbance may be split into two categories; those that cause short-term effects and those that cause longer-term effects. Short-term effects include immediate changes in behaviour precipitated by an external influence and may result in animals stopping feeding, socialising, resting or travelling (rapid changes in direction or stopping altogether). Long-term effects of repeated disturbance or harassment could include loss of weight or condition or reduced reproductive success. Sources of disturbance may include boat traffic, aircraft noise, fishing activity, naval sonar, seismic testing and surveying, aggregate extraction and/ or oil drilling and exploration [7].

Evans [7], Simmonds [5] and Berrow [13] among others recognise the potential for disturbance to a range of marine species, as a result of the growth in UK marine leisure traffic, and emphasise the need to ensure that vulnerable populations are protected. Simmonds [5] argues that there is considerable evidence in the UK of a growth in harassment of cetaceans, although the evidence cited is generally anecdotal and has not been borne out by a rise in prosecutions.

Other research has indicated a range of factors, which may be contributing to this purported rise in the number of incidents. Spradlin et al. [14] suggest that the growth in the marine ecotourism market has led to an increase in demand for 'a more interactive and close-up approach' to human encounters with marine mammals. In some cases, the target species for these activities are threatened or endangered, leading to concerns that additional stresses on vulnerable populations may result in rapid decline. Spradlin et al. [14] also suggest that a growing number of US marine mammal biologists are becoming increasingly concerned that marine mammals and humans are being placed at risk by activities which place heavy emphasis on close interactions, for example 'swim with dolphin' programmes. This concern was recently echoed in the UK when a young bottlenose dolphin took up residence in the Portland/Weymouth area, attracting considerable media and public attention.

\subsection{Reactions to disturbance-cetaceans}

Researchers have found a range of different behavioural responses by individual cetaceans and pods when in the vicinity of powered water craft, from no obvious reaction to displacement from feeding areas, shortened surfacing, loss of pod integrity and rapid scattering of individuals [15,5,7].

Blane and Jaakson [16] found that beluga whales in the St Lawrence River area, Canada, exhibited avoidance behaviour by prolonging intervals between surfacing, increasing their speed and bunching into groups. They also found that this avoidance 
behaviour intensified with an increase in boat traffic and was positively correlated with boat speed. Evans [7] notes that sounds may

... cause disruptions to the lives of cetaceans, distracting, annoying or even frightening them, as well as providing the potential for causing behavioral and physiological upset

He also stresses that there is a lack of data on the long-term effects of such sounds at the species, population and individual levels.

Richardson et al. [15], however, argue that most brief, short-term interruptions of normal behaviour have little effect on overall energy balance or reproductive performance, although they do note that physiological reactions may occur even if no overt behavioural response is detected. Although tolerance in these species may be considerable, Richardson et al. [15] also note that odontocetes such as bottlenose dolphins do sometimes react if confined, for example by shallow water, or if previously harassed by vessels.

\subsection{Reactions to disturbance-seals}

Richardson et al. [15] argue that in general, evidence concerning pinniped reactions to ships and boats is limited and anecdotal. Research does suggest, however, that seals often show great tolerance of vessel noise and traffic, although the short and longer term physiological responses have not been defined.

More recently, Westcott [11] investigated the extent to which grey seals were subject to anthropogenic disturbance when hauled out on rocks at two locations in south Devon. He found that sea state, climatic conditions and tidal variables were the key factors in determining whether seals hauled out or not and that persistent and close boat activity caused changes in haul-out behaviour which were not evident when seals remained undisturbed. Westcott's [11] data has been used in this research as a comparison with that gathered from other sources.

In contrast to Westcott's [11] findings, other research has shown that fur seals (Arctocephalus australis) will tolerate approaches by humans up to $10 \mathrm{~m}$, although tolerance depends not only distance but also on the behaviour of those approaching [17]. Taylor et al. [18] also found that grey seals (Halichoerus grypus) in captivity showed increased vigilance towards the approach of unfamiliar humans.

\subsection{Reactions to disturbance-basking sharks}

The impacts of human activities on basking sharks are little known and even more sparsely documented. One study in the South West has documented the short-term displacement responses of basking sharks when in the vicinity of a small boat with a $50 \mathrm{hp}$ engine [19]. Although the study was only able to investigate the reactions of one individual, it was found that angle of approach and engine noise were important 
factors in determining changes in behaviour such as cessation of feeding and displacement.

Davis et al. [20] note that the impacts of tourist activities on whale sharks within Ningaloo Marine Park (Western Australia) are unknown, and that statutory conservation agencies responsible for the management of the area are concerned that human-animal interactions should not impact adversely on the animals themselves.

\section{Methods}

This research represents a mix of quantitative and qualitative elements. In this context, it was felt appropriate to use a multi-method, case study approach [21], gathering a range of evidence to address the primary research question. By using a range of data sources, central themes and theories could be identified, examined and developed from different perspectives [22] and tested for triangulation, or convergence. This approach enables emergent theories to be continually assessed and refined throughout the research process [21,23].

The subject area itself is one of complexity and therefore no one type or source of data is likely to be sufficient to enable the research question to be answered in its fullest sense. Levels of reported incidents may or may not reflect a true picture of the 'real' situation in the field, for a number of reasons. By broadening the perspective and including questionnaire responses, an understanding could be gained of the motivation and ability of individuals to report perceived or actual harassment and disturbance incidents, their knowledge of existing protection measures and their understanding of their own levels of responsibility in managing the marine environment.

Mainstream data collection was organised into 3 key strands:

- A database of reported 'incidents' of harassment and disturbance was compiled.

- A series of semi-structured interviews were held with key individuals working in the marine environment.

- A questionnaire was delivered to a specifically targeted sample group, to explore perceptions of disturbance and understanding of current protection legislation.

Table 1

The sources of the reported incidents included in the database

\begin{tabular}{lr}
\hline Source & No. of records \\
\hline Devon \& Cornwall Police & 17 \\
Ministry of Defence Police & 3 \\
Seaquest Southwest & 11 \\
Marine Conservation Society & 1 \\
Whale and Dolphin Conservation Society (WDCS) & 1 \\
WDCS - Chasing Dolphins! & 20 \\
Westcott-Disturbance to grey seals at haul-out sites in South Devon & 53 \\
\hline
\end{tabular}




\subsection{Database}

Records of reported 'incidents' of harassment and disturbance to marine mammals and sharks were drawn from a number of diverse sources (Table 1). All available records were collected, from 1992 up to and including August 2002.

Incidents were categorised according to species and vessel type and the total number of incidents and the number of incidents per species per year were also calculated. Statistical analyses were not carried out on this data set, as the majority of reports were anecdotal and the data set contained inherent bias in terms of reporting procedures.

\subsection{Semi-structured interviews}

Five semi-structured interviews were held, with a mixture of face-to-face (recorded) and telephone (not recorded) interview techniques being used. Selection of participants was targeted at those with a strong background in marine conservation and wildlife legislation and with knowledge of harassment and disturbance issues. These included individuals working in the South West, and those working elsewhere in the UK. In order to allow comparisons to be made, a schedule of areas for discussion was drawn up, although this was not used as a rigid framework, but rather as a guide for both the interviewer and interviewee.

To enable content analysis, transcripts of each interview were reviewed and the substantive statements extracted. A series of 24 'themes' were developed from the transcripts and the substantive comments allocated to these themes. Where overlap occurred, comments were allocated to all relevant themes. Themes were then used to compare with the database and focus the questionnaire $[21,23]$.

\subsection{Questionnaire}

The questionnaire was designed to gather information on; respondent perception of harassment and disturbance of marine mammals and basking sharks, understanding of marine wildlife protection legislation and reactions to a range of marine management options. A mix of open and closed questions was used, allowing respondents to express their opinions fully in a number of key areas.

A systematic, non-random sampling method was used to identify target respondents for the questionnaire. Theoretical sampling [24] was used as it offered the opportunity to target a small group of individuals with knowledge of the issues under investigation and, as already discussed, statistical inference was not required. A total of 38 respondents were identified through membership of a Marine Ecotourism Forum, administered by Torbay Coast and Countryside Trust. The target group represented a diverse set of interests within the marine environment from those directly involved in marine conservation to those working in the leisure, tourism and commercial fishing industries. 
The majority of questionnaires were delivered by telephone, as this offered the advantage of a much better response rate, particularly important when dealing with a small, non-random sample [23,25]. In addition, a small number of questionnaires were delivered by e-mail, at the respondents' request, as they were unable to participate by telephone. Although questionnaires were delivered in a different context and may therefore have offered a different way for the individuals to express their views, the results have been included with those from the telephone questionnaires.

Questionnaire data was split into two groups for analysis; quantitative data which were analysed using simple frequency distributions and qualitative data which were allocated to the themes developed through the semi-structured interviews.

More complex statistical analysis of quantitative data was not carried out as the data gathered was largely nominal, non-parametric and therefore not susceptible to statistical analysis [22]. The sample size was also too small to allow a sufficient confidence level to be assigned to the data [25].

\section{Results}

\subsection{Database}

A total of 106 records of potential incidents in the South West were collected. Reported incidents were generally clustered around three main areas; Torbay, Plymouth and St. Ives (Fig. 1), with further incidents spread around the coastline from Weymouth (Dorset) to Braunton (north Devon).

Of the 53 records shown in Table 2, four involved basking sharks, 44 involved dolphins and five involved seals. There appear to be no obvious trends either between years or between species, although at least one incident involving dolphins was reported each year, whereas incidents involving basking sharks were only reported in 1995, 2000 and 2002. The database also shows that the majority of events occurred during the summer months from May to September. In terms of the types of vessel involved, motorboats were cited in 23 incidents, powerboats in 13 and jetskis in 11. A number of records also included reports of injuries to individual marine mammals and sharks. One particular bottlenose dolphin is often referred to as 'Benty', due to a misshapen dorsal fin. It is not clear whether this is an injury or a physical deformity. One report included a description of a vessel 'ramming' a large basking shark and several reports of vessel collisions with individual animals were also recorded.

\subsection{Semi-structured interviews}

Interviews were conducted with the following individuals:

Countryside Manager

Director of a cetacean charity

Marine Nature Reserve Manager 
Table 2

Summary of reported incidents 1992-2002 (excluding Westcott, 2000)

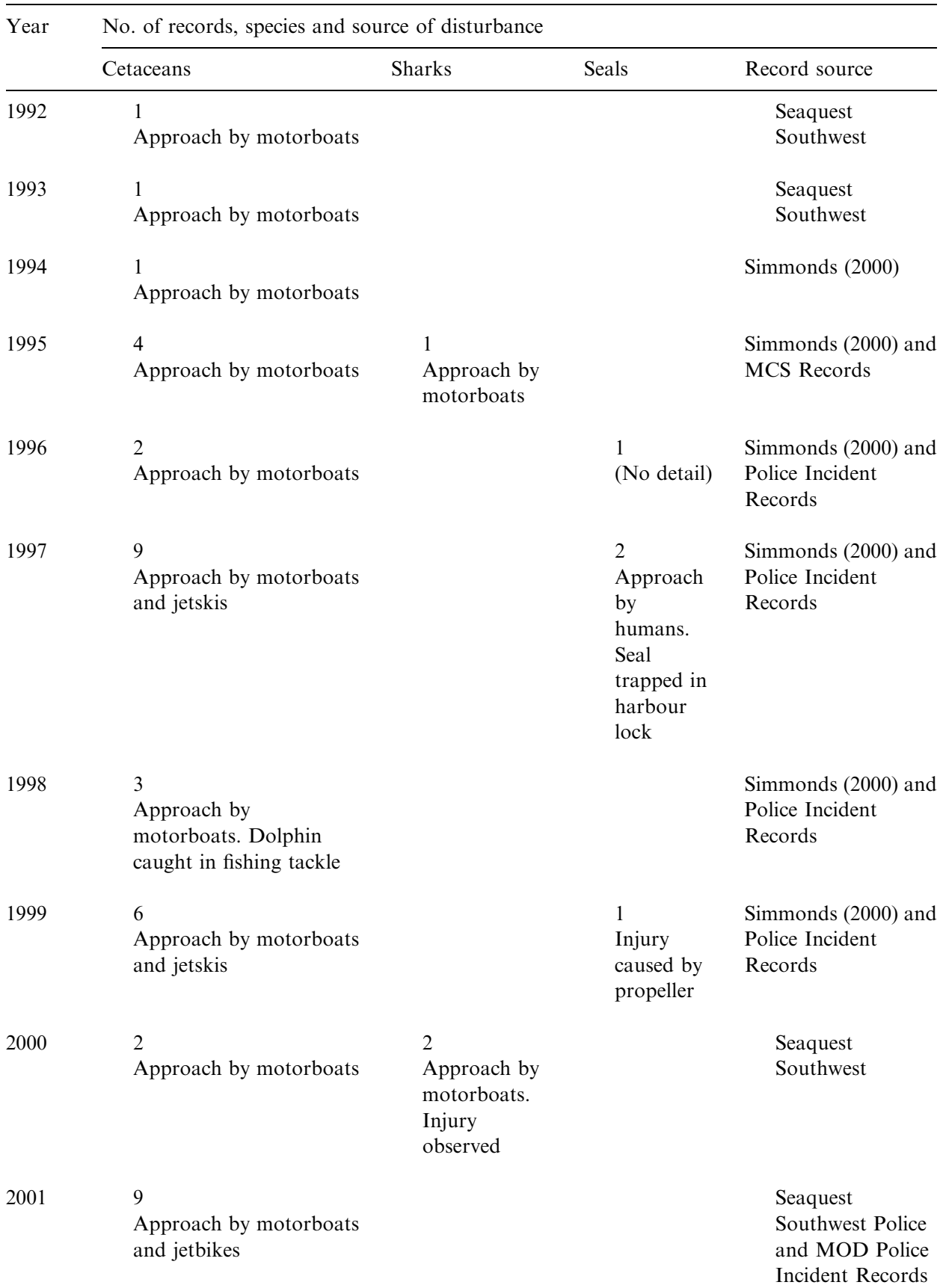


Table 2 (continued)

\begin{tabular}{|c|c|c|c|c|}
\hline \multirow[t]{2}{*}{ Year } & \multicolumn{4}{|c|}{ No. of records, species and source of disturbance } \\
\hline & Cetaceans & Sharks & Seals & Record source \\
\hline 2002 & $\begin{array}{l}6 \\
\text { Approach by motorboats } \\
\text { and jetskis }\end{array}$ & $\begin{array}{l}1 \\
\text { Approach by } \\
\text { surfers, non- } \\
\text { motorised } \\
\text { craft, divers }\end{array}$ & $\begin{array}{l}1 \\
\text { Other }\end{array}$ & $\begin{array}{l}\text { Police and MOD } \\
\text { Police Incident } \\
\text { Records, Seaquest } \\
\text { SouthWest, WDCS }\end{array}$ \\
\hline
\end{tabular}

\section{Police Wildlife Liaison Officer}

\section{Seal Expert}

Most interviewees felt that the image of cetaceans portrayed in the media has resulted in a 'special affinity' between humans and dolphins in particular, and that this is likely to engender a great deal of interest whenever this species is seen in inshore areas. One or two individuals also indicated that the reaction of individual dolphins in seeking out human contact could pose management dilemmas for those attempting to secure the health of the animal and the safety of the public. Issues regarding alternatives to boat based wildlife viewing were also raised as potential management measures.

In the context of the wider marine environment, one individual pointed out that pollution, bycatch and land run-off probably posed more of a threat to marine species than harassment and disturbance.

Several individuals referred to the current lack of incident reports and the logistical difficulties in gathering evidence in the marine environment. Most interviewees felt that the lack of awareness of the legislation had led to confusion amongst agencies and individuals as to who to report potential incidents to. Through the discussions, it also emerged that some of the key reasons why there have been no prosecutions to date are that there is a difficulty in defining harassment in legal terms, there is a lack of evidential data and a diversity of opinion on what constitutes 'harassment'. The approaches used elsewhere, for example in the US and South Africa, were raised as potential models for use in the UK, as were examples of management approaches used in terrestrial conservation, although their limited applicability in the marine environment was also noted. Most recognised the difficulty of effectively policing the marine environment and the lack of available resources to do so.

In terms of the process of enforcing existing legislation, several key points emerged which were common across all interviewees:

- Enforcement should be in partnership with a range of agencies already working in the marine environment.

- More information and intelligence is needed on current levels of vessel traffic and the behavioural responses of marine mammals and sharks to those vessels 
- Agency, NGO and other staff need to be more fully briefed on their role in providing information and working in partnership with enforcement agencies.

Terrestrial comparisons were also drawn with organisations such as the RSPB, which have had a significant impact in combating terrestrial avian related crime. Again, approaches which involve working in partnership with agencies already active in the marine environment were felt by many to be the way forward.

Education was discussed at some length and the use of education as a tool in managing public access to marine wildlife and disturbance was a key theme. Most interviewees were in agreement on the need for awareness raising, informing visitors of the need to protect these species and providing guidelines on how to behave when in the vicinity of marine wildlife.

In terms of the vessel types responsible, most individuals felt that motor vessels were usually to blame, citing specific examples such as holidaymakers with highpowered craft and little boat handling experience. One individual, however, felt that jet-skis had been unfairly blamed in many cases.

\subsection{Questionnaire}

Torbay, the geographic focus for the questionnaire, was identified from the database as an area with a high level of reported incidents. A systematic, nonrandom sampling method was used to identify target respondents for the questionnaire. Theoretical sampling [24] was used as it offered the opportunity to target a small group of individuals with knowledge of the issues under investigation and as already discussed, statistical inference was not required.

A total of 38 respondents were identified, through membership of a (now disbanded) Marine Ecotourism Forum administered by Torbay Coast and Countryside Trust. The target group represented a diverse set of interests within the marine environment, from those directly involved in marine conservation, to those working in the leisure, tourism and commercial fishing industries. The questionnaire focused on respondents' awareness of large marine animals, their knowledge of protection legislation, their opinions concerning harassment and measures that could be taken to prevent it. A total of 21 questionnaires were completed (response rate 55\%), 17 of which were by telephone and the remaining four by e-mail. Respondents represented a range of sectors and organisation types (Table 3) from registered charities to private sector companies.

Over $60 \%$ of respondents stated that they regularly or occasionally see cetaceans, seals or sharks in local inshore waters, although few were confident in assessing whether numbers of these key species were increasing or decreasing.

Although the majority $(72 \%)$ stated that they were aware of the legislation relating to cetaceans, sharks and seals, few could be specific on the detail or provisions, and many were unclear as to which species were protected. However, the majority felt confident that they would recognise an incident of 'reckless or intentional disturbance', although these respondents were not necessarily those who demon- 
Table 3

Questionnaire respondents' affiliations and the nature of these organisations

\begin{tabular}{|c|c|c|}
\hline Organisation & Type & Sector \\
\hline Astra Zeneca & Private company & $\begin{array}{l}\text { Contract Env. Research and } \\
\text { monitoring }\end{array}$ \\
\hline $\begin{array}{l}\text { Aquatic World Awareness } \\
\text { (PADI) }\end{array}$ & Diving-related charity & $\begin{array}{l}\text { Diving and conservation } \\
\text { (marine) }\end{array}$ \\
\hline Brixham Trawler Agents & Private company & $\begin{array}{l}\text { Commercial fish agents and } \\
\text { auctioneers }\end{array}$ \\
\hline Brixham Yacht Club & Members club & Watersports (yachting) \\
\hline $\begin{array}{l}\text { Department of the Environment, } \\
\text { Food and Rural Affairs }\end{array}$ & Government Department & Wildlife law enforcement \\
\hline $\begin{array}{l}\text { Devon Birdwatching and } \\
\text { Preservation Society }\end{array}$ & Wildlife orientated $\mathrm{NGO} /$ charity & Conservation (birds) \\
\hline Devon Sea Fisheries & Statutory Agency & Commercial fishing industry \\
\hline Devon Wildlife Trust & Wildlife orientated $\mathrm{NGO} /$ charity & Conservation (Devon wildlife) \\
\hline Divers Down & Private company & Watersports (diving) \\
\hline English Nature & $\begin{array}{l}\text { National statutory advisor to } \\
\text { Gov't }\end{array}$ & Conservation \\
\hline Environment Agency & Statutory Agency & Environmental protection \\
\hline Fishing Representative & Private individual & National Deep Sea Angling Rep \\
\hline International Sailing School & Private company & Watersports (yachting) \\
\hline Marine Conservation Society & Wildlife orientated $\mathrm{NGO} /$ charity & Conservation (marine) \\
\hline Nautical Venture Centre & Charity & $\begin{array}{l}\text { Outdoor activity based } \\
\text { experiences }\end{array}$ \\
\hline Paignton Zoo & Education and scientific charity & $\begin{array}{l}\text { Conservation (international } \\
\text { wildlife) }\end{array}$ \\
\hline Seahorse Trust & Wildlife orientated $\mathrm{NGO} /$ charity & $\begin{array}{l}\text { Conservation (seahorses and } \\
\text { wider) }\end{array}$ \\
\hline South West Tourism & Tourism association & Leisure \& tourism \\
\hline South West Water & Private company & $\begin{array}{l}\text { Aquatic environment (drinking } \\
\text { water) }\end{array}$ \\
\hline Trinity Sailing & Private company & Sailing \& sail training \\
\hline $\begin{array}{l}\text { Whale and Dolphin } \\
\text { Conservation Society }\end{array}$ & Wildlife orientated $\mathrm{NGO} /$ charity & $\begin{array}{l}\text { Conservation (cetaceans } \\
\text { worldwide) }\end{array}$ \\
\hline
\end{tabular}

strated any knowledge of the legislation. Sixty per cent said they had not observed a definite incident. In contrast, $52 \%$ indicated that they had witnessed what they perceived to be a possible incident. Just over half of the sample $(57 \%)$ felt that incidents involving dolphins were increasing, and many cited motor vessels, jet-skis and high-powered watercraft as those most often involved. Fig. 2 shows respondents' perceptions of changes in the number of incidents involving other marine species since 1992.

When asked about the reporting of incidents, most respondents indicated that, in the first instance, they would report potential incidents to the Coastguard Agency, with the RSPCA being the next most popular response. This result is surprising in that the RSPCA database does not appear to include any recorded incidents of harassment and disturbance in the marine environment. 


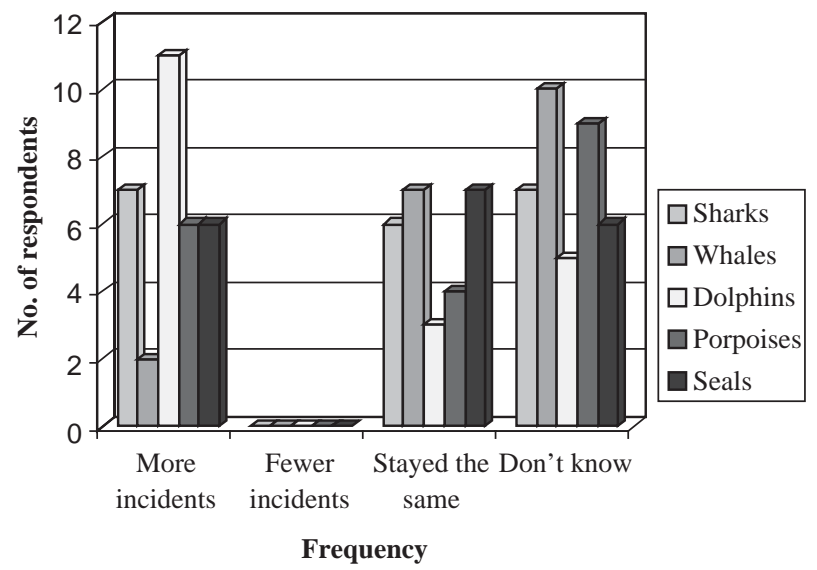

Fig. 2. Perceived changes in the frequency of incidents 1992-2002.

Table 4

Respondent preference for a range of management options

\begin{tabular}{|c|c|c|c|c|c|c|}
\hline \multirow[b]{2}{*}{ Option } & \multicolumn{6}{|c|}{ Score and number of responses } \\
\hline & $\begin{array}{l}1 \text { very } \\
\text { useful }\end{array}$ & 2 & 3 & 4 & $\begin{array}{l}5 \text { not useful } \\
\text { at all }\end{array}$ & $\begin{array}{l}0 \text { no } \\
\text { opinion } \\
\text { expressed }\end{array}$ \\
\hline Do nothing & 1 & & & & 20 & 1 \\
\hline Education & 18 & 3 & & & & \\
\hline Codes of conduct & 14 & 5 & 2 & & & \\
\hline Marine SAC & 7 & 8 & 4 & 1 & & \\
\hline Land-based whale-watching sites & 6 & 4 & 6 & 2 & 1 & 1 \\
\hline Eco-tourism accreditation & 9 & 8 & 3 & & 1 & \\
\hline Control speed of boats & 8 & 6 & 3 & 2 & 1 & \\
\hline $\begin{array}{l}\text { Limit distance between boats and } \\
\text { animals }\end{array}$ & 10 & 4 & 4 & 2 & & \\
\hline More police patrols & 5 & 3 & 6 & 4 & 1 & 1 \\
\hline Surveillance cameras & 3 & 3 & 6 & 3 & 5 & \\
\hline Total exclusion zone & 4 & 7 & 3 & 3 & 4 & \\
\hline
\end{tabular}

The majority of respondents felt that it was important to protect marine species from harassment and disturbance, and that they or their organisation had a role to play in protecting species. In terms of management approaches, education and codes of conduct emerged as the preferred methods from a list of options. Table 4 summarises the responses.

Surprisingly, $52 \%$ of respondents also felt that total exclusion zones would be useful as a management tool. Respondents were also asked if they had seen or used any codes of conduct before, for either terrestrial or marine species. Eighty per cent indicated that they had encountered them before and of those, most found them 
helpful and had used them, although some felt that there were too many individual species related codes in existence.

\section{Discussion}

\subsection{Disturbance}

If database evidence (see Table 2) alone is considered, the levels of incidents are low and the number of reported incidents per year does not appear to be changing significantly. Cetaceans, and in particular bottlenose dolphins, were the only mammals involved in reported incidents on an annual basis. Incidents involving basking sharks appear to be erratic, perhaps reflecting their limited, sporadic appearances along the South West coastline [3]. Incidents involving seals also appear to be a less regular occurrence despite their status as resident populations, although as Westcott [11] found, when a detailed observational study is made with clear parameters defining 'disturbance', the number of recorded incidents rises dramatically.

The questionnaire data suggest a much more complex situation. Just over a third of respondents felt that the number of incidents involving whales and seals had remained the same but over half felt that the number of incidents involving dolphins had risen. However, these results were tempered by a similar number of respondents who were unsure about the levels of incidents involving any of the target species. Respondents also showed an associated lack of confidence in assessing whether the numbers of individual mammals and sharks had increased or decreased over a 10year period. These results clearly reflect the difficulty in establishing the scale of the problem with any degree of confidence, and the low 'visibility' of marine wildlife crime in general.

A degree of consensus on the levels of disturbance did emerge amongst practitioners working in the marine conservation field. Responses to questions raised through both the semi-structured interviews and the questionnaires revealed that many felt the public, and in some cases professionals, had perhaps overreacted and that disturbance as an issue should be kept within the context of wider threats to the marine environment. Although these individuals felt that the extent of disturbance may have been exaggerated, all were in agreement that at certain times, disturbance and harassment did occur.

In terms of the type of vessel involved, database evidence suggests that motorboats, powerboats and jet skis were involved in the majority of reported incidents. To a certain extent, these results concur with the findings of other researchers. For example, Simmonds [5] cites many incidents of cetacean disturbance and harassment involving jet skis and other fast personal watercraft. Blane and Jaakson [16] also found that Beluga whales exhibited increased avoidance behaviour with an increase in vessel traffic and demonstrated a positive correlation between cetacean behaviour and boat speed. David [8] also cites similar responses by cetaceans to vessel traffic in the Mediterranean. As Evans [7] notes, this may be 
because cetaceans may not hear a Jet Ski, for example, until it is $450 \mathrm{~m}$ away, whereas a larger motorized vessel may be heard up to $3 \mathrm{~km}$ away. However, different data sources revealed different perceptions. Responses in the questionnaire pointed to a range of different vessel types from powerboats and jet skis to small fishing and leisure craft. Results from the semi-structured interviews also pointed to small engine leisure craft prevalent during the summer months and wildlife observation boats have also been seen to cause disturbance of seals.

\subsection{Legislation and reporting procedures}

Evidence for a lack of general awareness of current protection legislation clearly emerged from the semi-structured interviews and the questionnaires. This lack of knowledge was not restricted to any one sector but was spread across many and included those working in the marine environment. Clearly this is a key issue. If individuals are not aware of the legislation, they may witness a potential offence but remain unaware that they have done so. Under these circumstances, the level of reported incidents is unlikely to reflect the number of actual incidents. Several of those working in the wildlife legislation enforcement sector raised this as an issue and felt that it acted both as a top-down barrier; preventing authority figures from recognising the true nature and scale of the problem, and as a bottom-up barrier; preventing individuals from reporting incidents.

Some conservation organisations working within the marine environment have called for better legislative protection for cetaceans and sharks [5]. However, it is clear from all three strands of evidence that the existing legislation is not being used as effectively as perhaps it could be. This situation is borne out by the lack of successful prosecutions for marine wildlife crime. Higher levels of prosecutions for wildlife related crime within the terrestrial environment do not necessarily reflect a higher level of crime (although a higher number is likely in absolute terms), but do indicate a higher public profile and therefore a larger number of reported incidents. Recent amendments to the Wildlife and Countryside Act 1981 will go some way towards meeting the deficiencies within existing marine wildlife protection legislation, however, without an associated increase in the levels of both public and organisational awareness and co-operation, there is unlikely to be any improvement in the current situation. Additional measures such as enhanced Local Authority bylaw making powers, for example, may enable marine managers to address specific local issues, but this needs to be allied to an increased ability to police those byelaws effectively and an increase in available resources generally.

Another key issue emerging from this research is the lack of co-ordination between statutory agencies, NGO's and other groups involved in the management of the marine environment. Sightings and to some extent disturbance incident data is collated by a number of different organisations, some with geographic boundaries and it is often unclear whether multiple reports have been made to a range of different agencies. Unfortunately, there appears to be little in the way of formal agreements between these agencies and organisations to either share data, or 
collectively collate and analyse both sightings and incident data. This has contributed in no small part to the difficulty in establishing a true picture of the levels of disturbance.

\subsection{Management proposals}

This study has served to highlight the difficulty in establishing the levels and origins of harassment and disturbance to marine mammals and sharks in the South West. Although the findings should only be considered within this specific and geographic context, some recommendations can be made which may have broad applicability both within the region and to similar situations elsewhere.

Firstly, there was a clear lack of awareness and understanding amongst responsible agencies of the existing legislative frameworks. The first step must therefore be to promote widespread understanding of the legislation:

- What it is.

- What it covers.

- Who is responsible for implementing and enforcing it.

Allied to this, legal definitions of key terms such as 'reckless or intentional disturbance' have not been fully established within the context of the UK marine environment. This may have led to confusion and a lack of confidence amongst agencies in bringing forward potential cases for prosecution and clear, unambiguous definitions are therefore needed. The recently established PAW Marine Wildlife Enforcement Working Group (MWEWG) would appear to be a suitable vehicle to debate these issues and act as a platform for the dissemination of information.

Secondly, although numbers of reported incidents appear low it is not clear how well these represent the true situation. Although there appears to be a willingness to take responsibility for the marine environment, the public seems to be unsure of the mechanisms for reporting incidents. There is therefore a strong need to establish a high profile reporting procedure to encourage reporting and to ensure that key information is passed quickly and efficiently to law enforcement agencies. The PAW Marine Wildlife Enforcement Working Group would again appear to offer the best vehicle to identify a potential mechanism.

Thirdly, current levels of co-operation and data sharing between organisations could be improved, perhaps through the establishment of formal Memoranda of Understanding. This would allow those managing the marine environment to access important material such as sightings and incident data. With a better understanding of the life long behaviour of local marine mammal and shark species, the ecological basis for the strategic management of harassment and disturbance can be further strengthened.

Finally, and allied to the need for co-operation between agencies, is the need to reassess the effectiveness of existing codes of conduct. This could be introduced in conjunction with public education, which was thought to be one of the most significant features of any management option chosen. During this study, the issue of 
multiple codes of conduct was raised many times. Guidelines exist at local, regional, national and international levels and can either be geographically or species orientated and there is clearly considerable scope for confusion and duplication. Different recommendations are made by different codes in terms of the distance that should be kept between boats, swimmers and individual animals and some codes also suggest a time limit for interactions. It is therefore recommended that conservation and law enforcement agencies responsible for managing the marine environment work more closely together to amalgamate or combine codes, not only to prevent duplication but to ensure that the message is strengthened and disseminated as widely as possible. It was suggested that these guidelines should include clear information about appropriate distance limits, speed restrictions and existing legislation.

\section{Conclusion}

From the data available, the levels and origins of disturbance and harassment to marine mammals and sharks in coastal waters of the South West peninsula do not appear to be increasing or changing to any significant degree. However, the ambiguity of the incident data and the lack of conclusive triangulation between data strands serves to highlight one of the most important aspects emerging from this research, namely that confidence in the assessment is tempered by

- A lack of awareness of the provisions of UK legislation in relation to cetaceans, seals and sharks.

- A lack of incident reports and independently verifiable data.

- A lack of co-ordination and consensus amongst agencies and practitioners working within the field.

The marine species included within this research are all currently threatened or endangered. All are protected through legislative frameworks, primarily for this reason. Increasingly, visitors to the South West region are attracted by ecotourism including marine wildlife observation. Therefore, even if harassment and disturbance does not appear to be a priority issue in its own right, taken within the context of the wider environment and the growth in the marine leisure and ecotourism sectors, it is essential that the threat that this issue poses, and its contribution to existing pressures is understood. This work points to the need for greater clarity, for the public and professionals in this field, about the dividing line between enjoying marine wildlife and harassment.

\section{Acknowledgements}

With many thanks to all those who participated with the interviews and the questionnaire. Particular thanks are due to Nevin Hunter of the Partnership for Action against Wildlife crime (Marine Wildlife Enforcement Working Group). 


\section{References}

[1] Speedie CD.The Countryside and Rights of Way Act 2000 - the answer to the problems faced by marine wildlife through human disturbance? Police Wildlife Liaison Officers Conference, Exeter, 2001. Unpublished.

[2] Parsons ECM, Woods-Ballard A. Voluntary whale-watching codes of conduct: how effective are they in managing whale-watching in West Scotland? Paper presented to the Scientific Committee at the 53rd Meeting of the International Whaling Commission, 3-16 July 2001, London, SC53/WW6, 16pp.

[3] Speedie CD. Marine ecotourism potential in the waters of South Devon \& Cornwall. Clevedon, UK: Channel View Publications; 2002.

[4] International Ecotourism Society. Ecotourism statistical factsheet. Available from www.ecotourism.org/textfiles.stats (accessed 19/02/02).

[5] Simmonds MP. Chasing dolphins! A preliminary report on the failure of existing legislation to protect whales and dolphins from harassment and injury in UK waters. Bath, UK: The Whale and Dolphin Conservation Society, 2000. 20pp.

[6] Hunter N. Ensuring enforcement. Report prepared for the partnership for action against wildlife crime; Marine Enforcement Working Group, Temple Quay, Bristol, UK: PAW Secretariat, 2002.

[7] Evans PGH. Human disturbance of cetaceans. In: Taylor VJ, Dunstone N, editors. Exploitation of mammal populations. London: Chapman \& Hall; 1998. p. 376-94.

[8] David L. Disturbance to Mediterranean cetaceans caused by vessel traffic. In: Notarbartolo di Sciara G, editor. Cetaceans of the Mediterranean and Black Seas: state of knowledge and conservation strategies. Report to the ACCOBAMS Secretariat, Monaco, February 2002, Section 11, pp. $1-21$.

[9] Gubbay S. Coastal directory for marine nature conservation. Ross-on-Wye, UK: Marine Conservation Society, 1988. 319pp.

[10] Sims DW, Southall EJ, Quayle VA, Fox AM. Annual social behaviour of basking sharks associated with coastal front areas. Proceedings of the Royal Society, London B 2000;267:1897-904.

[11] Westcott S. Disturbance of grey seals (Halichoerus grypus) at haul-out sites: a report on the extent to which they suffer disturbance at two haul-out sites in South Devonshire, on what causes it and how it can be reduced. Dart Estuary Environmental Management, Devon Wildlife Trust, the National Trust, Torbay Coast and Countryside Trust, Slapton Field Studies Centre, 2000.

[12] Fowler HW, Fowler FG. The concise oxford dictionary. London: Oxford at the Clarendon Press, 1975. 1566pp.

[13] Berrow SD. Developing sustainable whale watching in the Shannon Estuary, Co. Clare. Ireland: Report for Shannon Dolphin and Wildlife Foundation; 2000.

[14] Spradlin TR, Barre LM, Lewandowski JJ, Nitta ET. Too close for comfort: concern about the growing trend in public interactions with wild marine mammals. Marine Mammal Society Newsletter 2001;9:3.

[15] Richardson WJ, Greene Jr. CR, Malme CI, Thomson DH. Marine mammals and noise. San Diego. US: Academic Press; 1995.

[16] Blane JM, Jaakson R. The impact of ecotourism boats on the St Lawrence Beluga Whales. Environmental Conservation 1994;21:267-9.

[17] Cassini MH. Behavioural responses of South American fur seals to approach by tourists: a brief report. Applied Animal Behaviour Science 2001;71:341-6.

[18] Taylor AA, Davis H, Boyle GJ. Increased vigilance toward unfamiliar humans by harbor (Phoca vitulina) and gray (Halichoerus grypus) seals. Marine Mammal Science 1998;14:575-83.

[19] Wilson E. Determination of boat disturbance on the surface feeding behaviour of basking sharks (Cetorhinus maximus). MSc. thesis, University of Plymouth, Plymouth, 2000. Unpublished.

[20] Davis D, Banks S, Birtles A, Valentine P, Cuthill M. Whale sharks in Ningaloo Marine Park: managing tourism in an Australian marine protected area. Tourism Management 1997;18:259-71.

[21] Gillham W. Case study research methods. New York: Real-World Research Series, Continuum, 2000. $106 \mathrm{pp}$. 
[22] McQueen RA, Knussen C. Research methods for social science. Harlow: Pearson Education, 2002. $245 \mathrm{pp}$.

[23] Arksey H, Knight P. Interviewing for social sciences. London: SAGE Publications, 1999. $208 \mathrm{pp}$.

[24] Walliman N.Your research project, a step-by-step guide for the first-time researcher. London: SAGE Publications, 2001. 322pp.

[25] de Vaus DA. Surveys in social research, 4th ed. London: UCL Press Ltd., 1996. $411 \mathrm{pp}$. 